\title{
ORGANIZING AND ATTENDING INTERNATIONAL CONFERENCES
}

\author{
Georgios Tsaparlis \\ University of loannina, Greece
}

"One learns his skill from others, now as in days of old; for 'tis no easy matter to discover the gates of verse unspoken before"

Bacchylides $^{1 *}$

Conferences, and especially international conferences, have become an integral part of a scientist's activities. The attendees are, as a rule, academics and their graduate students, with the latter usually accompanying their supervisors. In addition to recent graduates undertaking full-time research, the term graduate student can also apply to part-time research students, including teachers who often adopt an action research approach, using their own classes as the focus of their studies.

With most conferences, the emphasis tends to be on the presentation and discussion of the findings of recent research. However, in the case of science education, the dissemination of good practice can be considered equally important. Here, "there is little reason to do research, unless there is a pay-off in the classroom" (Hurd de Hart, 1991).

\section{Why Do Delegates Attend Conferences}

Established researchers like to attend conferences both to meet fellow researchers and to enable them to present important aspects of their published and/or ongoing research (especially when given the honor of being invited as plenary or keynote speakers). They can also offer advice and encouragement to younger and new researchers during informal discussions at conference coffee and lunch breaks.

Young graduate students are offered both an opportunity to present their own work and to meet and share knowledge and experiences with fellow students working on similar projects, possibly providing opportunities to develop collaborative projects. Even established researchers can often initiate useful collaborations as a result of exchanges at a conference. In the case of delegates for whom English is not their mother tongue, they have the chance to practice both their speaking and listening skills.

It is my belief that all doctorate students should attend at least two international conferences, presenting their own work at, at least one of them, as part of their graduate studies. One might be less prescriptive in the case of masters' students, who (in my opinion) should attend at least two local/national conferences. Of course, because of the reduced costs (and a drastically reduced fee - see below) both graduate students and active teachers should not miss the opportunity to attend international conferences which are organized in their own country.

In the case of active teachers, we need to distinguish two main groups: teachers with knowledge and experience of the implications of education research to classroom practice (these teachers often hold a post-

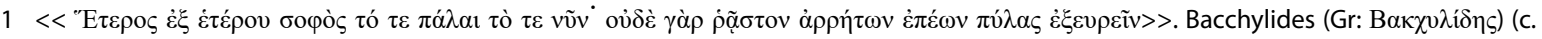
$520-450$ BC) was a Greek lyric poet. Translated by David A. Campbell. 
ISSN 1648-3898/Print/

ISSN 2538-7138/Online/

graduate degree in science education) and teachers with limited appreciation of pedagogical developments. The unfamiliarity of some teachers with the findings from science education research and/or their inability to apply them to the design and organization of their teaching strategies and procedures is a problem that has been documented in the literature (Costa, Marques, \& Kempa, 2000).

Retired academics should also be encouraged to attend conferences to share their wisdom and experience with younger researchers. Such retired academics are likely to lack funding to attend conferences, so there is a case for drastically reduced fees in their case (see below).

\section{Content of a Conference}

The usual format for a conference involves both oral and poster presentations, with plenary and keynote lectures being an important component of the oral presentations. The oral presentations usually run in parallel sessions that are organized into structured symposia proposed by their organizers or under themes that are decided and organized by the conference organizers. Symposia often bring together people who are pursuing similar themes of research or even those who are already collaborating in established research groups. Workshops with more applied themes (such as international projects or new education methods or curricula), inviting audience participation, may also form part of conferences. These tend to be particularly popular with teachers, while new researchers often find workshops dealing with research methodologies useful.

Time dedicated to questions constitutes an essential integral part of oral presentations. Unfortunately question time is often restricted because of the tendency of speakers to overrun their allocated times. Attendees, who, instead of asking questions relevant to the presented topic, take up time (often long) to present their own views or worse to openly criticize the importance of the reported research, can also misuse question times. Such discussions could better be achieved by exchanges with presenters during conference breaks.

Various types of work can be presented at conferences. Some involve communicating the preliminary findings of ambitious projects, where the ultimate aim is to publish later the full results in an international journal. Others report the results of less ambitious work, with the goal of publishing a full paper in the conference proceedings, although the proceedings may also include parts of very important work. The symposia and/or workshops can offer the opportunity to present ongoing international collaborative projects or new curricula or even new books. Some conferences organize pre-conference workshops that run before the official opening of the conference, usually one day before.

The need for a large number of parallel sessions poses a serious problem for very large conferences (such as NARST and ESERA). For example, in the case of the 2017 ESERA conference, which was organized in Dublin, Ireland, 17 topics/strands were covered (see Table 1), with as many as 22 sessions running in parallel. This meant that the most a delegate could attend was $1 / 22^{\text {th }}$ of the program (compared to $0 / 22^{\text {th }}$ for an absentee from the conference). On the other hand, a small conference such as ECRICE 2018 (which was organized in Warsaw, Poland), included in the main only double parallel sessions and a considerable number of plenary sessions.

Table 1. The 17 strands of the ESERA 2017 conference.

\begin{tabular}{cl}
\hline Strand & Strand theme/title \\
\hline 1 & Learning science: Conceptual understanding \\
2 & Learning science: Cognitive, affective, and social aspects \\
3 & Science teaching processes \\
4 & Digital resources for science teaching and learning \\
5 & Teaching learning sequences and innovative interventions for teaching and learning science \\
6 & Nature of science: history, philosophy and sociology of science \\
7 & Discourse and argumentation in science education \\
8 & Scientific literacy and socio scientific issues \\
9 & Environmental, health and outdoor science education \\
10 & Science curriculum and educational policy
\end{tabular}




\begin{tabular}{cl}
\hline Strand & \multicolumn{1}{c}{ Strand theme/title } \\
\hline 11 & Evaluation and assessment of student learning and development \\
12 & Cultural, social and gender issues in science and technology education \\
13 & Pre-service science teacher education \\
14 & In-service science teacher education, continued professional development \\
15 & Early years science education \\
16 & Science in the primary school \\
17 & Science teaching at the university level \\
\hline
\end{tabular}

For the benefit of local attendees, who may lack a command of English, it is advisable to use simultaneous translation into the national language for plenary and possibly keynote lectures or at least to also show power-point presentations in the national language (using two projectors and two screens). It is less desirable to attempt to provide a piece by piece translation of a lecture, because this will take up precious time and cause an interruption in the flow of a talk.

\section{Oral and Poster Presentations}

A crucial distinction is made between oral and poster presentations. When submitting proposals, applicants are asked to indicate their preferred form of presentation, though a request for an oral presentation may not always be able to be satisfied, due to quality criteria or time constraints. Very often, there is also a restriction on the number of allowed oral proposals per participant (for instance up to two), with an additional number (1-2) of allowed posters.

Organizers often use a grading scheme, as a yardstick to monitor the quality of proposals, which can be used by reviewers: if a proposal gets, say a mark of over $60 \%$ it will be accepted as an oral presentation, while a mark between 40 and $60 \%$ leads to acceptance for a poster. Proposals marked under $40 \%$ are likely to be rejected. Traditionally, therefore, posters have tended to be considered inferior to oral presentations, but this is not necessarily the case. There are several reasons why either presenters or organizers may prefer the use of a poster to an oral presentation, without the work being considered in any way inferior. Posters may be considered desirable for presentation of complex topics or very specific topics, likely to be of interest to only small numbers of delegates. In some cases, presenters themselves may even prefer to make a poster presentation due to shyness or weakness in spoken English.

In any case, it is important that poster sessions should be given a proper positioning in the program by allocating to them dedicated sessions, where no oral presentations have been scheduled. Sometimes poster presenters are allocated a short time (such as two or three minutes or a maximum of eight power-point slides per presenter), at the beginning of the poster sessions, to orally introduce their posters. Another practice is for a group of attendants led by a group leader (possibly their research supervisor) to visit selected posters and ask the presenter to give a short oral presentation in situ, which is followed by questions and a discussion. In some conferences, a prize may be awarded for the best poster(s). This is likely to be judged by a special committee of experienced participants.

It is probably good practice not to separate the oral and poster presentations in the conference proceedings, but rather have all proposals grouped only according to their theme or strand. However, a label marking them as an oral or a poster presentation may usually be included.

\section{Peer-Reviewed Conferences and Conference Proceedings}

The process of peer reviewing the submitted abstracts or synopses is very important, so it is this, to a large extent, that will determine the quality of the conference. This is a particularly important practice where publication of papers in peer-reviewed conference proceedings can count towards job tenure or promotion.

Members of the 'scientific committee' of the conference carry out the reviews, using criteria set by the organizers. The reviewers are often asked to rate various features of proposals (e.g. originality, methodology, results, implications, language and references), so that an overall mark can be assigned to each proposal. These 
marks are then used to decide whether a proposal should be accepted and what form the presentation should take (oral or poster - see above). Revision may be required, on the basis of the reviewers' comments and recommendations, before a proposal is accepted.

Some conferences only publish in print and/or in electronic form abstracts of the presentations, while others also publish proceedings with full papers. At one time, these were in print but nowadays they tend to be only in electronic form. For instance, ESERA (the "European Science Education Research Association") publishes on its website the e-proceedings of its conferences, about one year after a conference, with open-access. A page limit (8-10 pages) is usually set for the full papers to be published in the proceedings. [Proceedings of the most recent (2017) ESERA conference, published in September 2018, contained 2381 pages.] In addition to the proceedings, ESERA also publishes a book (published by Springer), containing papers from the conference, selected by the organizers based on various criteria.

\section{Other Conference Formats}

Traditional conferences tend to be speaker-centered, allowing little or no time for questions and discussions. Even conference breaks are not sufficiently long to allow delegates attending subsequent sessions to complete a meaningful discussion with a speaker. Indeed, the most valuable aspect of many conferences is the opportunity to meet old and new acquaintances and finding out more about their current work.

The American "Gordon Conferences" use a modified format, with invited speakers only. Each speaker is given about one hour to talk and this is then followed by a long session for questions and discussion. The "Dortmund Symposia", which were initiated and organized for many years by the late professor of chemistry education Hans-Juergen Schmidt, adopted a similar format.

A recent conference format (the "unconference") is strictly participant-centered, adopting communication methods supported by the learning literature (Brazil, 2018). It shifts the focus from speakers to participants, by allowing participants to make suggestions and agree about a theme of common interest, at the beginning of the conference. Knowledgeable individuals may then deliver short talks, followed by discussion. The 'unconference' may even split into smaller subgroups, each tackling a subtopic. It might be a bit risky to adopt such a free format for a large conference, but an 'unconference' could easily constitute a small part of a standard conference, with proposals being submitted in advance by potential coordinators.

\section{Social Events}

Each international conference is organized in a particular city and country, which many, possibly the majority of participants, might not have visited before. Conferences, therefore, can offer both time for sightseeing and opportunities to experience the local cultural life. Ideally, delegates can extend their stay by arriving early or staying on for a few days after the conference has finished. Unfortunately, most people do not have the available time and/or money to do this, so the only way to satisfy the touristic urge may be to skip some of the conference. For this reason, it is advisable for organizers to include, for example, a half-day tour of the city, in the organized program.

I recently attended the "European Conference on Research in Chemical Education" (ECRICE 2018) in Warsaw, and the program included both an afternoon guided tour of the city and an evening attending a Chopin concert. A further evening was spent at the conference dinner, and all these, plus the opening reception, coffee breaks and lunches, were included in the registration fee.

\section{Finance and Registration Fees of Conferences}

Last, but not least, it is important to consider the cost of organizing and attending an international conference. Organizing a conference can be a complicated and onerous task, for which those undertaking the organization receive no payment. Finance is a very important aspect of the organization of any conference. Numerous costs arise for the organizers, such as the cost of material in the conference folder, costs for hiring lecture rooms, for the welcome reception, for coffee breaks and lunches, and most importantly for covering expenses of invited and key-note speakers.

The organization can be simpler, if the conference is organized in a big hotel, which includes full confer- 
ence facilities (including a big lecture hall plus some smaller meeting rooms), rather than at a university. This has the particular advantage that most participants can stay in the hotel, thus allowing more contact time between the delegates. Although in principle this arrangement may appear more expensive, the organizers may be able to make a deal with the hotel, so that the use of lecture rooms and presentation equipment is free providing that a minimum number of hotel rooms are booked for stay by participants. Of course, this approach is only likely to be feasible for large conferences. The American "National Association of Research in Science Teaching" (NARST) follows this practice. One disadvantage is that participants do not have the chance to get to know a local university.

Organizers have two sources of funding to cover the expenses: 1) the registration fee; 2) potential sponsors (such as university, ministry of education, local municipalities, publishing houses, producers of laboratory equipment, manufacturers of food, etc.). Sponsors can be an uncertain source of support and their contributions may come relatively late, uncomfortably close to the conference dates. On the other hand, the registration fee needs to be set early, to enable potential delegates to calculate the cost of their participation and decide if they can afford to attend. Registration fees can be high, for example, the 2017 ESERA conference set an early-bird registration fee of $€ 495$ (including membership of the association), with a corresponding reduced fee $(€ 235)$ for students. The ECRICE in 2018 had a $€ 350$ early-bird fee and a slightly reduced one $(€ 300)$ for students and retired researchers.

Many participants (academics, graduate students, and possibly school teachers) can cover the whole or part of their expenses through funding provided by their institutions, grant agencies, or projects in which they participate. However, students, teachers, and, as a rule, retired researchers have no access to sources of funding and must cover the costs themselves. Taking into account the high registration fees and the cost of travel and accommodation, attending a conference can be very expensive. It cost a teacher, who was a former graduate student of mine, more than a month's salary to attend and make a presentation at a recent European conference. As a result, many people who cannot obtain any funding cannot and do not attend international conferences. National conferences can be easier to afford and attend because of much lower travel costs and often much lower registration fees, such as euro 20-30!

There are two ways, in which people with no funding might be encouraged to participate in international conferences. Firstly, through a drastically reduced registration fee or secondly through the provision of grants by organizations and associations. In this latter case, priority should be given to (i) young jobless students (aged say under 28), (ii) teachers, and (iii) retired researchers. In the case of distinguished retired researchers, the possibility of a waiver of the registration fee might even be considered. The availability of cheap accommodation, such as student residences, is also likely to be important.

However, it is probably more important to consider ways to reduce registration fees in general. Firstly, there is surely no need to supply participants with expensive conference bags; many of us have lots of them already. A cheap envelope, containing the participant's badge, a list of participants, the printed conference program plus a little promotional and touristic material would suffice. A book of abstracts and conference proceedings should of course be provided, but nowadays this can be in electronic form only. The conference dinner and any organized tours may not be included in the registration fee, with delegates having the option to pay for these separately. Coffee breaks and lunches can also prove costly and organizers might consider the possibility of asking participants to pay for their own meals and coffee. A substantial saving could be made if the whole, or part, of the costs for invited speakers could be avoided. Perhaps these speakers could be asked at the beginning if they might be able to get funding (total or in part) towards their costs.

I believe that in Europe we could have registration fees as low as $€ 100-200$, and reduced fees of $€ 50-100$. Local teachers who are not giving a presentation should be offered a special low fee of $€ 30-50$. The aim must surely be to encourage and increase the number of participants, both from the host country and abroad.

Note: The author of this editorial has, to date, attended a large number of international conferences, including major ones, such as ESERA, NARST, and ICCE/IUPAC conferences. He was the organizer both of the $5^{\text {th }}$ ECRICE and of an international symposium on particulate and structural concepts of matter. He was also the chairperson of the organizing committee of a Greek national science education conference. Finally, he has been invited speaker and member of the scientific committees for many international and Greek conferences. 
ISSN 1648-3898/Print/

ISSN 2538-7138/Online/

\section{Acknowledgement}

The author is grateful to Dr Bill Byers who read the manuscript and made suggestions for a better presentation.

\section{References}

Brazil, R. (2018). The art of crafting conferences. Chemistry World (the RSC monthly news magazine), 15 (8) 56-57.

Costa, N., Marques, L., \& Kempa, R. F. (2000). Science teachers' awareness of findings from educational research. Chemistry Education Research and Practice, 1 (1) 31-36.

Hurd de Hart, P. (1991). Issues in linking research to science teaching. Science Education, 75 (6) 723-732.

Received: September 28, 2018

Accepted: November 16, 2018

Georgios Tsaparlis

M.Sc., Ph.D., FRSC, Professor Emeritus of Science Education,

University of loannina, Department of Chemistry, GR-451 10,

loannina, Greece.

E-mail: gtseper@cc.uoi.gr 